\title{
Induction of proinflammatory cytokine production in intervertebral disc cells by macrophage-like THP-1 cells requires mitogen-activated protein kinase activity
}

\author{
Jung Jae Park, MD, Hong Joo Moon, MD, PhD, Jin Hyun Park, BS, Taek Hyun Kwon, MD, PhD, \\ Youn-Kwan Park, MD, PhD, and Joo Han Kim, MD, PhD \\ Department of Neurosurgery, Guro Hospital, College of Medicine, Korea University, Seoul, South Korea
}

\begin{abstract}
OBJECTIVE To determine the role played by mitogen-activated protein kinase (MAPK) signaling in the interactions between macrophages and intervertebral disc (IVD) cells, it was hypothesized that MAPK inhibition would modulate the production of the proinflammatory cytokines associated with inflammatory reaction in IVD cells.
\end{abstract}

METHODS Human annulus fibrosus (AF) and nucleus pulposus (NP) cells were cocultured with phorbol myristate acetate-stimulated macrophage-like THP-1 cells, with and without SB202190 (a p38- $\alpha$ and $-\beta$ inhibitor), SP600125 (a c-Jun N-terminal kinase [JNK] inhibitor), and PD98059 (an extracellular signal-regulated kinase [ERK] 1/2 inhibitor). The cytokines in conditioned media from cocultured and macrophage-exposed (nemotic) cells were assayed using enzymelinked immunosorbent assays (ELISAs).

RESULTS Interleukin (IL)-6 and IL-8 were secreted in greater quantities by the cocultured cells compared with naive IVD cells and macrophages (MФ) cultured alone. The tumor necrosis factor (TNF)- $\alpha$ and IL-6 levels produced by the NP

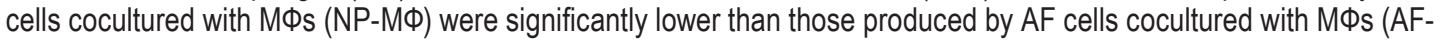
MФ). SB202190 dose-dependently suppressed IL-6 secretion by AF-MФ and NP-MФ cocultures, and $10 \mu M$ SB202190 significantly decreased IL-6 and IL-8 production in nemotic AF and NP pellets. SP600125 at $10 \mu \mathrm{M}$ significantly suppressed the production of TNF $\alpha$, IL- 6 , and IL-8 in AF-MФ and NP-MФ cocultures and significantly suppressed IL-1 $\beta$ production in the NP-MФ coculture. Administration of $10 \mu \mathrm{M}$ PD98059 significantly decreased IL-6 levels in the AF-MФ coculture, and decreased the levels of TNF $\alpha$ and IL-8 in both the AF-MФ and NP-MФ cocultures.

CONCLUSIONS The present study shows that inhibitors of p38 MAPK effectively controlled IL-6 production during inflammatory reactions and that JNK and ERK1/2 inhibitors successfully suppressed the production of major proinflammatory cytokines during interactions between macrophages and IVD cells. Therefore, selective blockade of these signals may serve as a therapeutic approach to symptomatic IVD degeneration.

http://thejns.org/doi/abs/10.3171/2015.3.SPINE14729

KEY WORDS intervertebral disc degeneration; cytokines; mitogen-activated protein kinases; SB202190; SP600125; PD98059

$\mathrm{L}$ OW-BACK pain is a major musculoskeletal disorder that affects many adults at some point in their lives. Although multiple spinal structures, including intervertebral discs (IVDs), facet joints, vertebral bodies, ligaments, and muscles, can be sources of low-back pain, IVD degeneration after an inflammatory reaction is a major initial cause of chronic, intractable low-back pain. ${ }^{21} \mathrm{In}$ a study examining the discs of patients with discogenic low-back pain, the abundance of macrophages in the IVD was strongly associated with the presence of inflammatory reactions, the formation of granulation tissue, and the triggering of repair processes. ${ }^{21}$ IVD degeneration after an inflammatory reaction is characterized by progressive loss of proteoglycans, dehydration, alterations in the structure of the nucleus pulposus (NP), and neovascularization of (with nerve ingrowth into) the annulus fibrosus (AF)., ${ }^{1,21}$

ABBREVIATIONS AF = annulus fibrosus; $A F-M \Phi=A F$ cells cocultured with MФs; CCK-8 = Cell Counting Kit-8; CM = conditioned media; ELISA = enzyme-linked immunosorbent assay; ERK = extracellular signal-regulated kinase; FBS = fetal bovine serum; IL = interleukin; IVD = intervertebral disc; JNK = c-Jun $\mathrm{N}$-terminal kinase; M

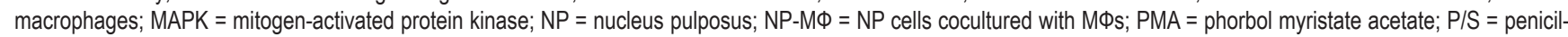
lin/streptomycin; TBS-T = Tris-buffered saline and Tween 20; TNF = tumor necrosis factor.

SUBMITTED July 23, 2014. ACCEPTED March 25, 2015.

INCLUDE WHEN CITING Published online October 2, 2015; DOI: 10.3171/2015.3.SPINE14729. 
Previously, we showed that macrophages played a major role in the production of inflammatory mediators in the $\mathrm{AF}$, and that such mediators might be associated with the development of discogenic low-back pain via annular inflammation. ${ }^{9}$ However, the role played by macrophages in the development of symptomatic IVD degeneration, including the NP, has not yet been investigated.

Cytokines are involved in development of inflammatory reactions and are responsible for a significant proportion of the pathology of symptomatic IVD degeneration. Of the cytokines, interleukin (IL)- 6 and IL- 8 are produced at levels that are orders of magnitude greater than tumor necrosis factor (TNF) $-\alpha$ and IL-1 $\beta$ in coculture models, although much attention has been paid to the roles played by TNF $\alpha$ and IL- $1 \beta$ in disc disease. ${ }^{9}$ IL-6 is closely associated with the development of neurological symptoms in patients with autoimmune inflammatory diseases such as rheumatoid arthritis and systemic lupus erythematosus. ${ }^{11}$ IL-6 production in the disc tissue may significantly contribute to neurogenic pain. ${ }^{13}$ In addition, IL-8 production may be associated with neovascularization of and inflammatory reactions in painful discs. Thus, knowledge of the cytokine production pathways of IVD cells would aid mechanistic evaluations of the processes involved in symptomatic IVD degeneration.

During inflammation, proinflammatory cytokines activate several intracellular signaling pathways via the actions of mitogen-activated protein kinases (MAPKs). ${ }^{5,15}$ These enzymes are evolutionarily conserved and involved in cell signaling and gene expression. ${ }^{8}$ MAPKs are activated by phosphorylation and transduce a broad range of extracellular stimuli into diverse intracellular responses by exerting both transcriptional and nontranscriptional regulation. The MAPK family includes p38, the c-Jun Nterminal kinase (JNK), and the extracellular signal-regulated kinase 1/2 (ERK1/2), all of which trigger signaling cascades. These pathways can be stimulated by various stressors, including ultraviolet and other forms of irradiation, osmotic stress, heat shock, proinflammatory cytokines, chemotherapeutic drugs, and certain mitogens. Recently, there has been considerable interest in identifying intracellular inhibitors of p38 MAPK for the treatment of rheumatoid arthritis. ${ }^{4}$ Furthermore, many inhibitors have been developed and studied in a large number of clinical trials in several chronic inflammatory diseases. Therefore, the MAPK pathways are all molecular targets for new drug development, and inhibitors of MAPKs will undoubtedly be one of the next groups of drugs developed for the treatment of human disease. However, the influence of MAPK pathways in discogenic pain during inflammatory reactions has not been studied. We hypothesized, in the present study, that MAPK inhibition selectively modulates the production of proinflammatory cytokines, which play roles in development of symptomatic IVD degeneration.

\section{Methods}

\section{Isolation and Culture of AF and NP Cells}

Human AF and NP cells were isolated from the disc tissues of patients ( 2 female and 4 male patients). These tissues were removed during elective surgery to treat de- generative spinal disease (Grades II-III on the Pfirrmann grading system). Our institutional review board approved our work. Tissue specimens were placed in sterile Ham's F-12 medium (Gibco-BRL) containing 1\% (wt/vol) penicillin/streptomycin (P/S; Gibco-BRL) and 5\% (vol/vol) fetal bovine serum (FBS; Gibco-BRL). After washing, the $\mathrm{AF}$ and NP regions were carefully defined, separately resected, and digested for 60 minutes in F-12 medium containing $1 \%(\mathrm{wt} / \mathrm{vol}) \mathrm{P} / \mathrm{S}, 5 \%(\mathrm{vol} / \mathrm{vol}) \mathrm{FBS}$, and $0.2 \%(\mathrm{wt} /$ vol) pronase (Calbiochem), followed by overnight incubation in $0.025 \%$ (wt/vol) collagenase I (Roche Diagnostics). Both cell suspensions were filtered through sterile nylon mesh ( $70-\mu \mathrm{m}$ pore diameter), centrifuged, resuspended, and cultured in F-12 medium with $10 \%$ (vol/vol) FBS and $1 \%$ (wt/vol) $\mathrm{P} / \mathrm{S}$ (culture medium) in a humidified atmosphere of $5 \%$ (vol/vol) $\mathrm{CO}_{2}$ at $37^{\circ} \mathrm{C}$ (see Fig. 1).

A pellet culture system was used to mimic the 3D cellular interactions of the in vivo environment, allowing quantitative comparison of cytokine production by both cell types. The IVD cells in the pellet were surrounded by a rigid fibrous coat, thus mimicking the physiological environment. ${ }^{16}$ Furthermore, the majority of the human IVD cells retained their native phenotype in this 3D system and expressed a marker gene both in vitro and in vivo. ${ }^{16}$ The pellet is easy to manipulate in terms of Western blotting, exhibits low cell division rates, and allows cytokine secretion to be measured. Cells at $95 \%$ confluence were removed from flasks by treatment with $0.05 \%$ (wt/vol) trypsin/EDTA (Gibco-BRL), and the AF and NP cells (2 $\times 10^{5}$ cells $/ \mathrm{ml}$ ) were resuspended in culture medium in individual $15-\mathrm{ml}$ polypropylene conical tubes, centrifuged (5 minutes at 224g) to pellet aggregates, and incubated for 7 days.

\section{Culture of Activated Macrophage-Like THP-1 Cells}

Human acute monocytic leukemia (THP-1) cells (Korean Cell Line Bank) are a type of mononuclear phagocyte that are converted into activated macrophage-like cells on incubation with phorbol myristate acetate (PMA) ${ }^{20}$ PMA exerts pleiotropic effects on the differentiation of normal and malignant cells and induces the differentiation of human promyelocytic cells into macrophages, which exhibit phagocytosis and secrete proinflammatory cytokines. ${ }^{22,25,26}$ Thus, the THP cell line may serve as a useful model for the study of the mechanisms of maturation or differentiation of monocytes into macrophages and also the biochemical mechanism(s) of phagocytosis. Previously, we found that such activated macrophage-like cells produced proinflammatory factors, including TNF $\alpha$ and IL-1 $\beta .{ }^{9}$ In the present work, THP-1 cells were maintained in RPMI 1640 medium (American Type Culture Collection) supplemented with $10 \%$ (vol/vol) FBS, $1 \%$ (wt/vol) $\mathrm{P} / \mathrm{S}$, and $0.05 \mathrm{mM} 2$-mercaptoethanol (Sigma-Aldrich) and stimulated to differentiate into macrophage-like THP-1 cells by treatment with $160 \mathrm{nM}$ PMA (Sigma-Aldrich) for 72 hours prior to coculture.

\section{Coculture of Macrophage-Like Cells and IVD Cells}

PMA-activated macrophage-like THP-1 cells were removed from the culture flasks by trypsinization and placed 


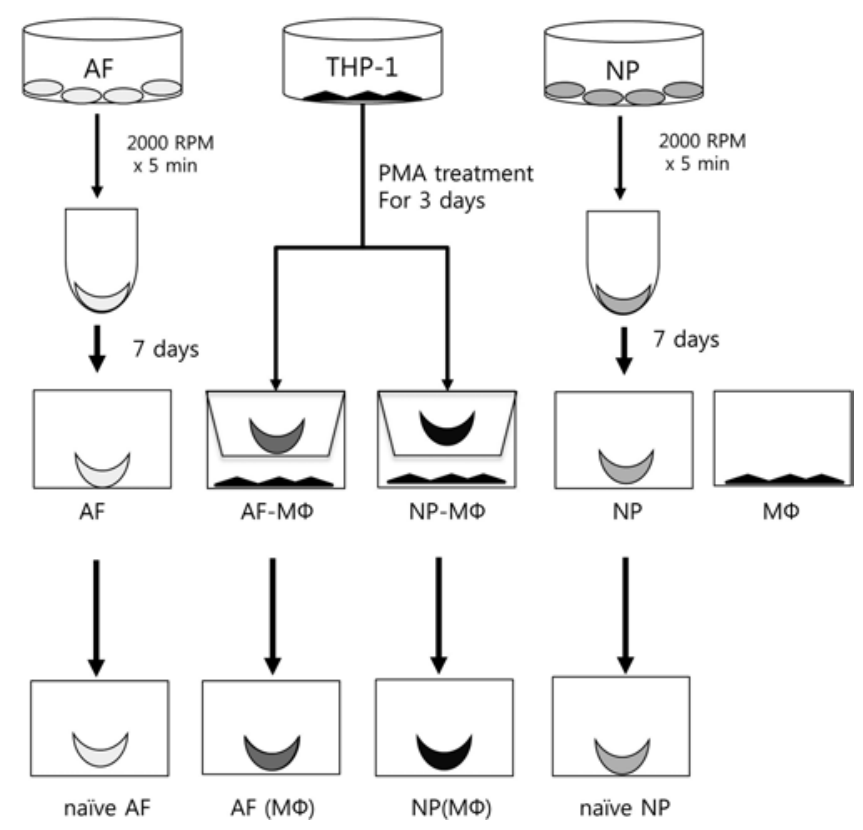

FIG. 1. Schematic representation of the in vitro coculture experiment. $\mathrm{AF}=$ human annulus fibrosus pellet $\left(2 \times 10^{5}\right.$ cells/well); $\mathrm{AF}(\mathrm{M} \Phi)=$ macrophage-exposed (nemotic) AF pellet; $M \Phi=$ activated macrophagelike THP-1 cells $\left(1 \times 10^{5}\right.$ cells/well); NP = human nucleus pulposus pellet $\left(2 \times 10^{5}\right.$ cells/well $) ; \mathrm{NP}(M \Phi)=$ nemotic NP pellet; PMA $=160 \mathrm{nM}$ phorbol myristate acetate.

in the wells of 24-well plates at a density of $1 \times 10^{5}$ cells/ well in 1-ml volumes of F12/Dulbecco's modified Eagle medium with $1 \%$ (vol/vol) FBS and $1 \%$ (wt/vol) P/S (this was a serum-starved medium). NP and AF pellets were added to the cell culture inserts $(0.4-\mu \mathrm{m}$ pore diameter, Becton Dickinson Labware) and placed in the wells with macrophage-like cells to implement the in vitro inflammatory reaction. The inserts prevented phagocytosis, but permitted the media to be shared and the materials secreted from one cell type to interact with the other (thus, we established a noncontact coculture system).

To evaluate the effects of inhibition of the MAPK transduction pathway, we used SB202190 (Merck), a selective inhibitor of p38- $\alpha$ and $-\beta$, SP600125 (Merck), a competitive inhibitor of JNK, and PD98059 (Cell Signaling Technology), an MEK1/2 [MAPK/ERK1/2] inhibitor. SB202190, SP600125, and PD98059 were dissolved in dimethylsulfoxide and simultaneously added at different levels $(0.1,1$, and $10 \mu \mathrm{M})$ to different coculture wells. Conditioned media (CM) from the cells that were cocultured for 48 hours were collected for cytokine quantitation using enzyme-linked immunosorbent assays (ELISAs).

\section{Inhibition of the MAPK Transduction Pathway in Macrophage-Exposed AF and NP Pellets}

To evaluate the effects of inhibition of the MAPK transduction pathway on macrophage-exposed (nemotic) AF and NP cells, 2 doses (1 and $10 \mu \mathrm{M})$ of SP600125, SB202190, and PD98059 were added to wells containing nemotic AF and NP pellets, and incubation continued for 48 hours. Next, $\mathrm{CM}$ were stored at $-80^{\circ} \mathrm{C}$.

\section{Western Blotting}

Human AF and NP cells were collected, washed twice with ice-cold Hank's balanced salt solution (GibcoBRL), and resuspended and centrifuged in the same solution $(14,240 g ; 5$ minutes). The pelleted cells were suspended in Lysis Buffer (iNtRON Biotechnology), held for 30 minutes on ice, and cellular debris was removed by centrifugation at $14,240 \mathrm{~g}$ for 15 minutes. Protein-containing supernatants were subjected to Western blotting. Protein concentrations were estimated using the BCA Protein Assay Kit (Thermo Fisher Scientific), and all samples were stored at $-80^{\circ} \mathrm{C}$. Protein samples $(10 \mu \mathrm{g})$ were subjected to reducing sodium dodecyl sulfate polyacrylamide gel electrophoresis (SDS-PAGE) and transferred to polyvinylidene fluoride membranes with a low-fluorescence background (Millipore Corporation). The membranes were blocked in $5 \%$ (wt/vol) skim milk for 1 hour and (separately) probed overnight at $4{ }^{\circ} \mathrm{C}$ with the following antibodies: anti-JNK (ab64334, Abcam); anti-ERK (ab17942, Abcam); antiphospho-JNK (ab4821, Abcam); antiphospho-ERK (ab4819, Abcam); antiphospho-P38 (ab4822, Abcam); and antiactin (A5316, Sigma Aldrich) in 5\% (wt/vol) skim milk in Trisbuffered saline and Tween 20 (TBS-T). After washing, the membranes were incubated for 1 hour with the appropriate secondary antibody that was diluted 1:20,000 in 5\% (wt/ vol) skim milk in TBS-T. The bands were visualized using an X-ray film processor (Konica SRX-101A). Each blot was performed twice, and representative scans are shown.

\section{ELISAs}

The concentrations of TNF $\alpha$, IL-1 $\beta$, IL- 6 , and IL- 8 in $\mathrm{CM}$ were assayed by ELISA using commercially available kits (R\&D Systems) according to the manufacturer's protocols.

\section{Cytotoxicity Test}

The Cell Counting Kit-8 (CCK-8) (Dojindo Laboratories) was used to measure the cytotoxicity of the MAPK inhibitors according to the manufacturer's protocol. Briefly, $5 \times 10^{3}$ cells were seeded in each well of 96-well plates and exposed to various doses of SP600125and PD98059. The CCK-8 assay was performed 48 hours later.

\section{Statistical Analyses}

Data are expressed as the means \pm standard error of regression of the results of 3 to 5 individual experiments using independent cell cultures. Every individual experiment involved 4 or 5 samples. The p values were calculated using the Student t-test, and a p value $<0.05$ was considered to indicate statistical significance.

\section{Results}

\section{Production of Inflammatory Mediators in Cocultures}

To demonstrate differences in inflammatory mediator synthesis by AF and NP pellets, both cell types were cocultured with macrophage-like cells for 48 hours (Fig. $2)$. Naive AF and NP cells did not produce detectable amounts of TNF $\alpha$, IL-1 $\beta$, IL-6, or IL-8 as reported in a previous study (data not shown). ${ }^{9,10}$ The levels of TNF $\alpha$ and IL-6 were significantly lower in the CM of the NP 
A

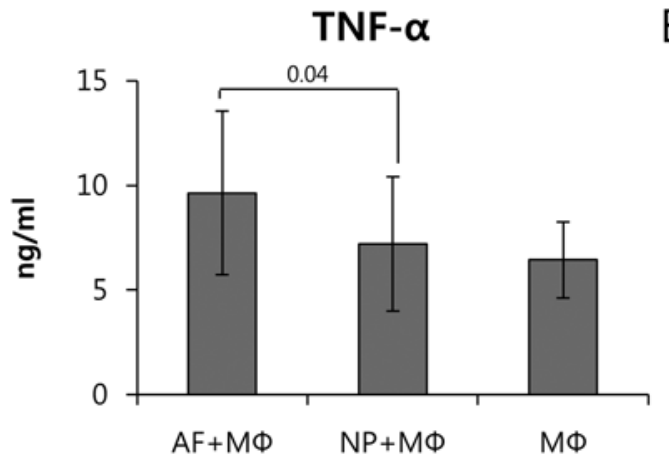

C

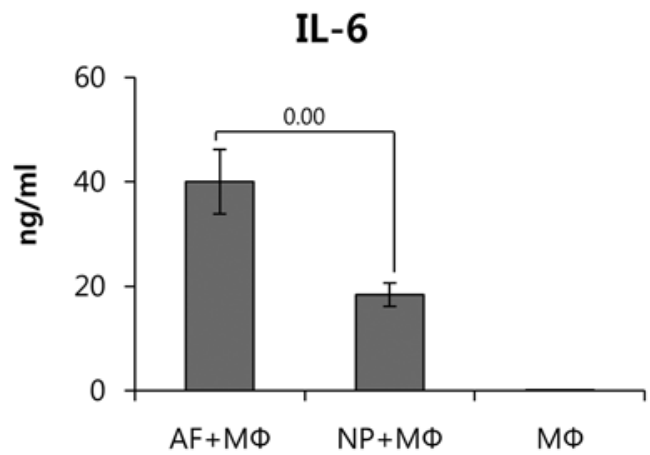

B

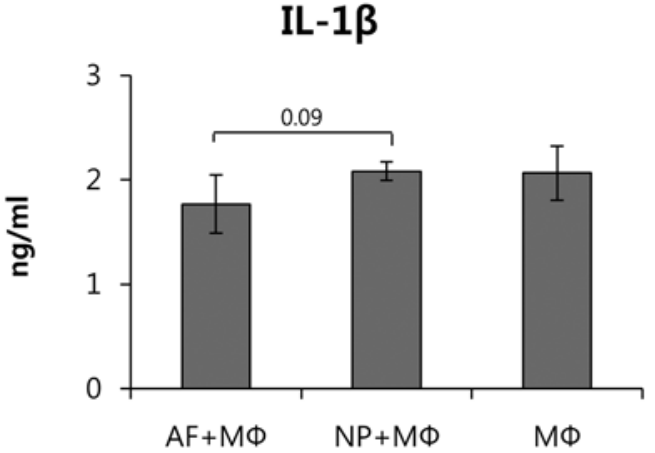

D

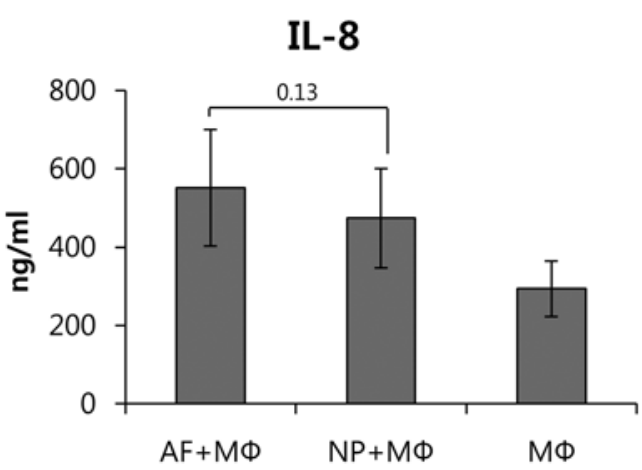

FIG. 2. Inflammatory mediator production in cocultured cells. The levels of TNF $\alpha$ (A) and IL-6 (C) decreased significantly in the CM of NP-MФ (TNFa: $7.19 \pm 3.210 \mathrm{ng} / \mathrm{ml} ; \mathrm{lL}-6: 18.36 \pm 2.24 \mathrm{ng} / \mathrm{ml}$ ) compared with the levels produced by AF-MФ (TNFa: $9.64 \pm$ $3.90 \mathrm{ng} / \mathrm{ml} ; \mathrm{lL}-6: 40.00 \pm 6.16 \mathrm{ng} / \mathrm{ml}$ ). The levels of IL-1 $\beta$ (B) and IL-8 (D) did not significantly differ in either group of cocultures ( $\mathrm{p}$ $>0.05$ ). Naive AF and NP cells did not produce detectable amounts of TNF $\alpha$, IL-1 $\beta$, IL-6, or IL-8 (data not shown).

pellets that were cocultured with macrophage-like cells $(\mathrm{NP}-\mathrm{M} \Phi)(\mathrm{TNF}: 7.19 \pm 3.210 \mathrm{ng} / \mathrm{ml}$; IL-6: $18.36 \pm 2.24$ $\mathrm{ng} / \mathrm{ml}$ ) compared with the levels produced by AF pellets cocultured with macrophage-like cells (AF- MФ) (TNFa: $9.64 \pm 3.90 \mathrm{ng} / \mathrm{ml}$; IL-6: $40.00 \pm 6.16 \mathrm{ng} / \mathrm{ml})$. The $2 \mathrm{co}-$ cultures differed strikingly in terms of IL-6 production, although the levels of IL-1 $\beta$ and IL- 8 did not differ significantly.

\section{Cytotoxicity and Effects of Inhibitors of the MAPK Transduction Pathway}

We previously investigated the effectiveness of SB202190, ${ }^{10,23}$ and, thus, in the present work, we evaluated the cytotoxicities and effects of SP600125 and PD98059 (only) on AF and NP cells using the CCK-8 assay and Western blotting. Inhibitor-treated cells did not significantly differ from the controls in terms of viability, and the MAPK inhibitors successfully suppressed the phosphorylation of MAPK (Fig. 3).

\section{Inhibition of Proinflammatory Cytokine Production via the MAPK Transduction Pathway During Coculture}

SB202190 dose-dependently decreased IL-6 levels in the $\mathrm{CM}$ from the NP-M $\Phi$ and AF-M $\Phi$ cocultures (Fig. 4). SP600125 at $10 \mu \mathrm{M}$ significantly decreased the levels of TNF $\alpha$, IL-6, and IL-8 in the CM from AF-M $\Phi$ and NP-M $\Phi$ cocultures, and significantly suppressed IL-1 $\beta$ production in the NP-M $\Phi$ coculture (Fig. 5). Adminis- tration of $10 \mu \mathrm{M}$ PD98059 significantly decreased IL-6 levels in the AF-M $\Phi$ coculture and decreased the levels of TNF $\alpha$ and IL-8 in both the AF-MФ and NP-M $\Phi$ cocultures (Fig. 6).

\section{Inhibition of IL- 6 and IL-8 Production via the MAPK Transduction Pathway in Nemotic AF and NP Pellets}

SB2021090 at $1 \mu \mathrm{M}$ significantly decreased IL-6 and IL-8 production in nemotic AF pellets, and $10 \mu \mathrm{M}$ significantly decreased IL- 6 and IL- 8 production in nemotic AF and NP pellets (Fig. 7A and B). SP600125 did not significantly affect IL-6 or IL-8 production in nemotic AF and NP pellets (Fig. 7C and D). PD98059 at $10 \mu \mathrm{M}$ significantly decreased IL-6 production in nemotic NPs (Fig. 7E and $\mathrm{F}$ ).

\section{Discussion}

Low-back pain is an enormous medical and socioeconomic burden in modern society. Although many etiologies of low-back pain are known, an important feature is IVD degeneration, including that of the AF and NP cells, after an inflammatory reaction. In the present study, we found that the interactions between macrophages and IVD cells triggered the production of large amounts of cytokines. Specifically, AF cells, which are known pain generators, produced larger amounts of TNF $\alpha$ and IL-6 than NP cells. Our results also demonstrate the ability of the potent and selective MAPK inhibitors SB202190, PD98059, and 
A

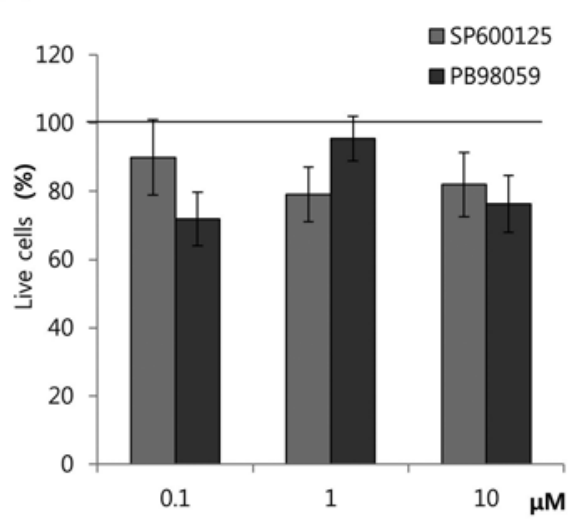

B

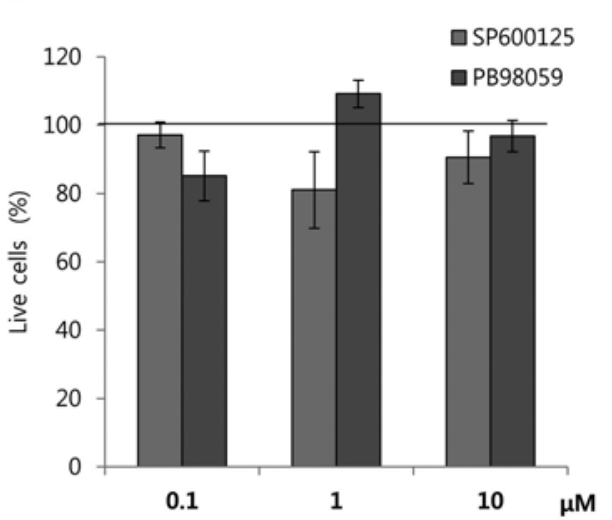

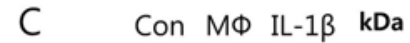

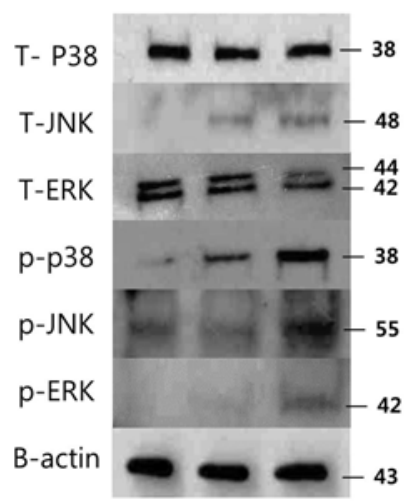

D
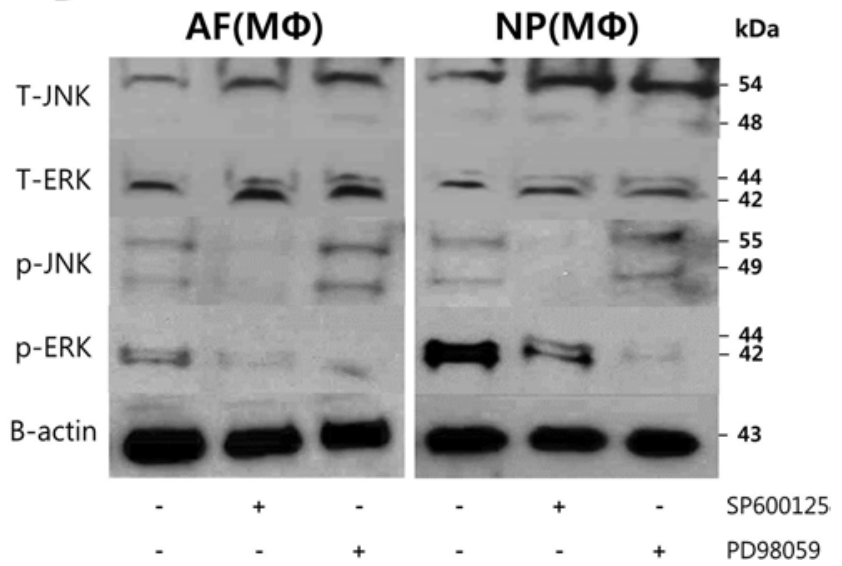

FIG. 3. Cytotoxicity and effectiveness of the inhibitors of the MAPK transduction pathway. Because we previously investigated the effectiveness of SB202190, the cytotoxicities and effects of SP600125 and PD98059 (only) on AF (A) and NP (B) cells were measured using the CCK-8 assay and Western blotting, respectively. The control and treatment groups did not differ significantly in

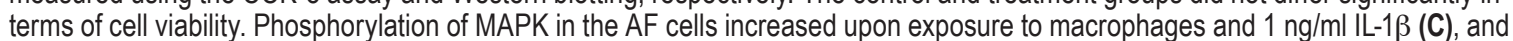
10- $\mathrm{MM}$ MAPK inhibitors successfully suppressed MAPK phosphorylation in macrophage-exposed (nemotic) AF and NP cells (D).

SP600125 to differentially reduce proinflammatory cytokine levels when macrophage-like cells interact with IVD cells or nemotic IVD cells. These results suggest that controlling the MAPK pathway might prevent or mitigate the development of symptomatic IVD degeneration.

In agreement with previous studies, morphologically NP cells resembled chondrocyte-like cells, which are more rectangular in shape compared with the AF cells in monolayer cell culture, while AF cells resembled fibroblasts which are spindle-shaped., ${ }^{7,16}$ Upon interaction with macrophage-like cells, AF cells produced significantly larger amounts of IL-6 than NP cells, although no difference in IL-8 production was noted. In previous studies, IL-6 was shown to induce mechanical and thermal hyperalgesia when injected into rat paw. ${ }^{3}$ Others have found a clear correlation between the degree of tactile allodynia and extent of IL-6 upregulation, irrespective of the animal model used. ${ }^{2,13}$ It is well known that AF is the major pain generator of IVD cells. Anatomically, the AF has sensory nerve endings in the outer one-third and is located next to the dorsal root ganglia. ${ }^{17}$ In the present study, AF cells produced larger amounts of IL-6 than NP cells in response to macrophage exposure. These results suggest that, apart from the anatomical characteristics, the AF may perceive pain after injury because of pain-related cytokine production, a key event in the early stage of intractable discogenic pain.

We showed that specific inhibitors of p38 MAPK effectively inhibited IL-6 production during interaction between macrophage-like cells and IVD cells. A previous study found that p38 MAPK in IVD cells was activated by phosphorylation in response to proinflammatory stimulation. ${ }^{14}$ We found that the p38 MAPK pathway was more closely linked to IL-6 production than to that of any other cytokine, in agreement with the findings of previous studies. ${ }^{10,19,23}$ We also showed that p38 MAPK inhibitors at 10 $\mu \mathrm{M}$ effectively blocked IL-6 and IL-8 production in both nemotic AF and NP cells. It has been reported that p38 MAPK stabilized IL-6 and IL-8 transcripts. ${ }^{12}$ In human NP cells, the phospho-p38 MAPK- $\alpha$ levels were markedly increased after exposure to TNF $\alpha$ or IL-1, although the total amount of p38 MAPK did not change. ${ }^{22}$ Therefore, we hypothesized that the deactivation of $\mathrm{p} 38$ MAPK by SB202190 would diminish the levels of IL-6 and IL-8 produced during inflammation of IVD cells, and that IL-6 production is much more sensitively regulated by the $\mathrm{p} 38$ 
A

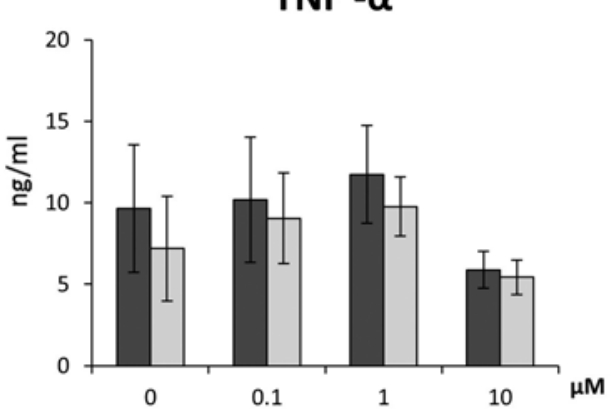

C

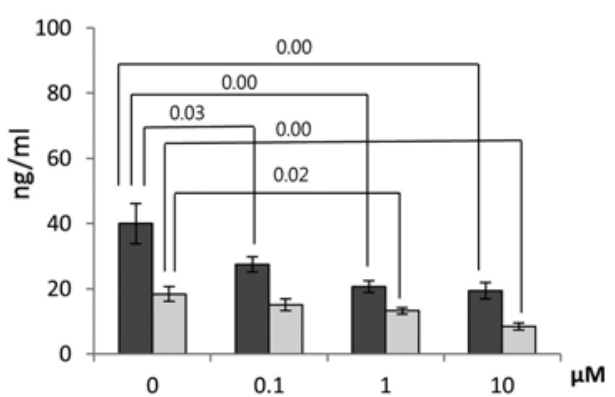

B

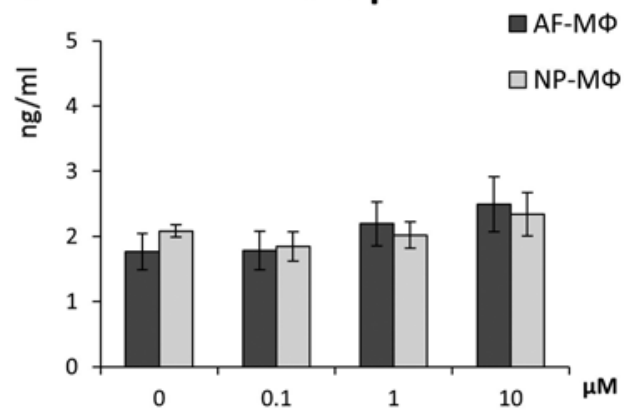

D

IL-8

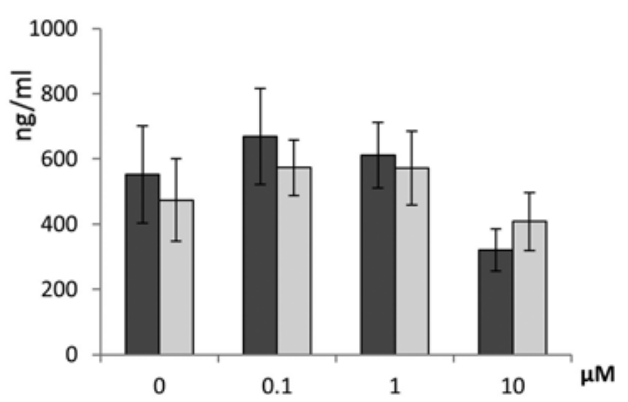

FIG. 4. Inhibition of the p38-MAPK transduction pathway during coculture. SB202190 dose-dependently decreased IL-6 (C) production in CM from NP-MФ and AF-MФ cocultures. SB202190 at $10 \mu \mathrm{M}$ tended to decrease TNF $\alpha$ (A) and IL-8 (D) production, but did not suppress IL-1 $\beta$ production $(B)(p>0.05)$.
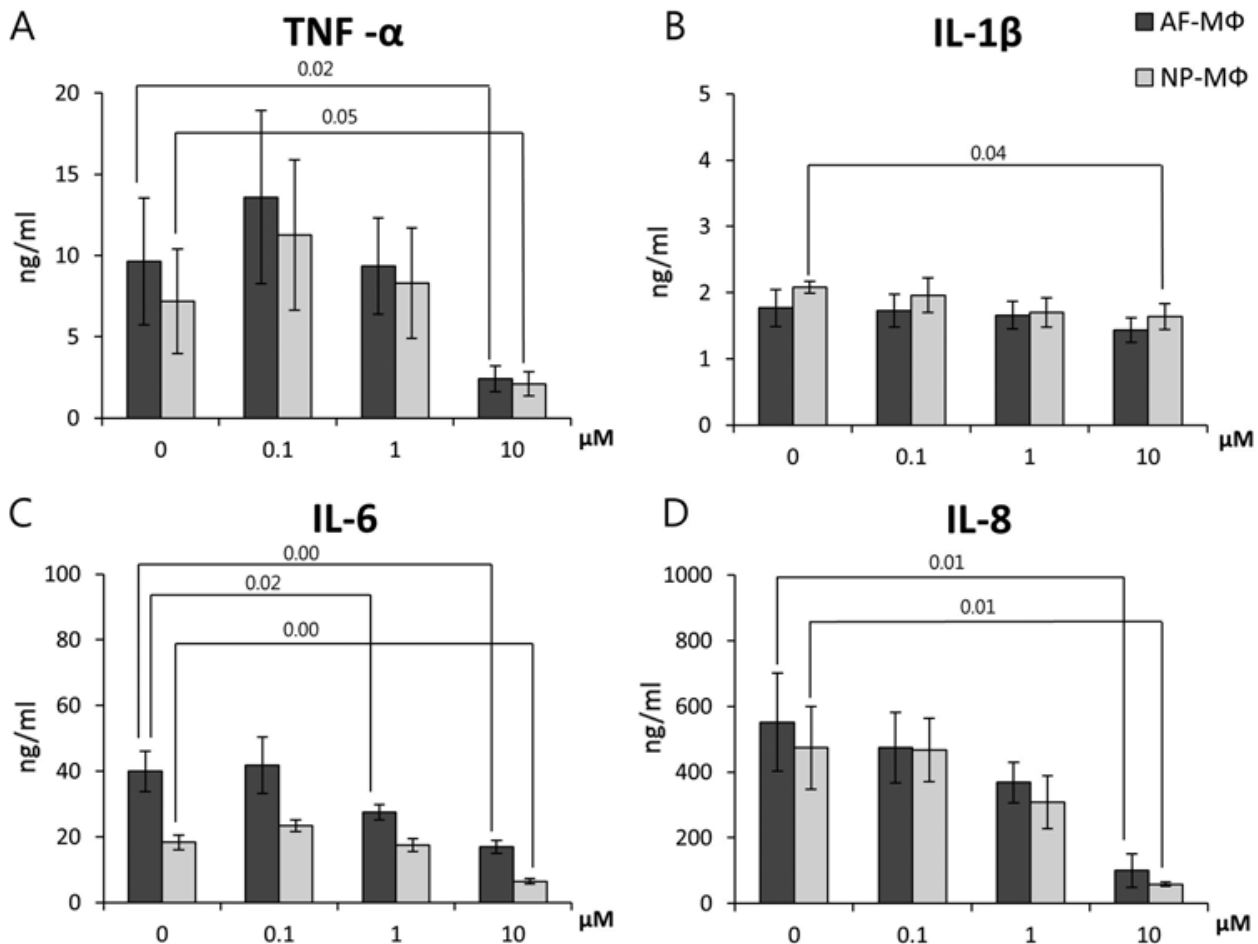

FIG. 5. Inhibition of the JNK1/2 MAPK transduction pathway during coculture. SP600125 at $10 \mu \mathrm{M}$ significantly decreased the levels of TNF $\alpha$ (A), IL-6 (C), and IL-8 (D) in the CM of NP-MФ and AF-M $\Phi$ cocultures, and significantly suppressed IL-1 $\beta$ (B) production in the NP-M $\Phi$ coculture. 
A

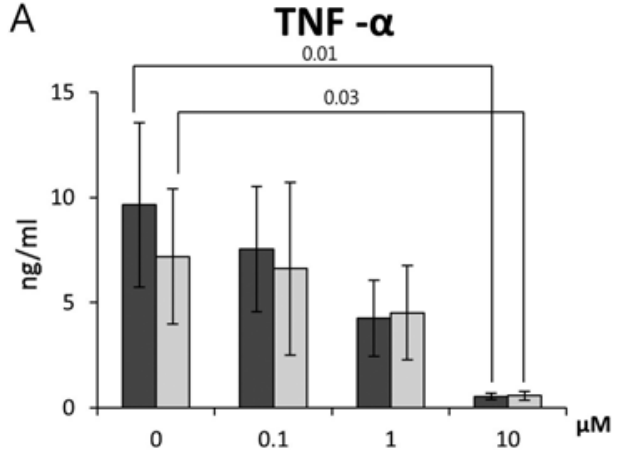

C

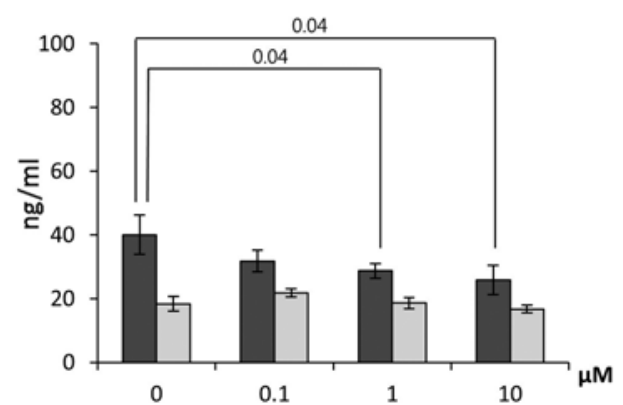

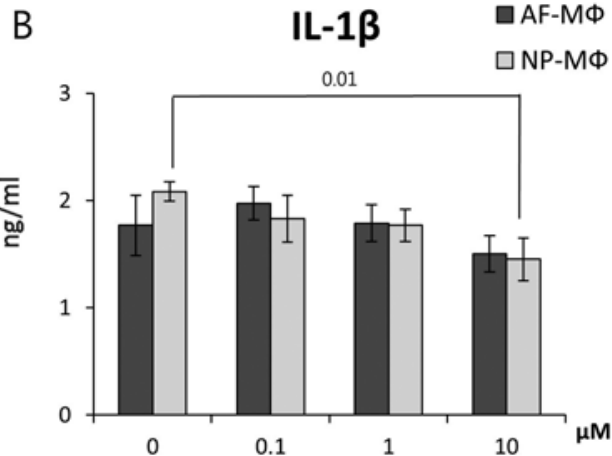

IL-8

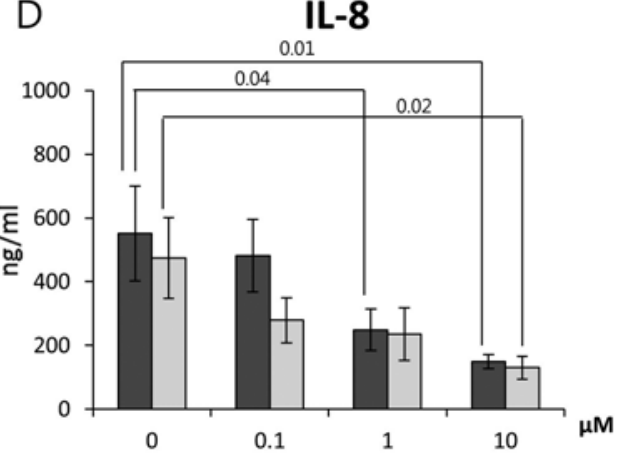

FIG. 6. Inhibition of the ERK1/2 MAPK transduction pathway during coculture. PD98059 dose-dependently decreased IL-6 (C) and IL-8 (D) production in AF-MФ coculture, and 10- $\mu$ M PD98059 significantly decreased the levels of TNF $\alpha$ (A) in NP-M $\Phi$ and AF$\mathrm{M} \Phi$ cocultures and the level of IL-1 $\beta$ (B) in NP-M $\Phi$ coculture.

MAPK pathway than any other MAPK pathway. These results promise that $\mathrm{p} 38 \mathrm{MAPK}$ inhibitors could be the first selective drugs for discogenic pain rather than the other MAPK blockers. We also found that ERK1/2 MAPK was constitutively activated and may be primarily responsible for TNF $\alpha$ and IL-8 production in cocultures, more so than the production of IL-1 $\beta$ and IL- 6 . ERK1/2 MAPK has been shown to be involved in the transcriptional activation of nuclear factor $\kappa B s$, which are factors that are constitutively activated during inflammation that mediate the transcriptional upregulation of proinflammatory genes. ${ }^{6,27}$ The ERK1/2 MAPK inhibitor PD98059, which blocks ERK1/2 via deactivation of MEK1/2, exerted inhibitory effects on TNF $\alpha$, IL-6, and IL-8 production during the coculture of macrophages and IVD cells, but these protective effects did not extend to nemotic IVD cells.

The stress-activated JNK protein kinase is phosphorylated (in response to extracellular stimuli) at conserved threonine and tyrosine residues and plays regulatory roles in inflammation. ${ }^{5,24}$ Inhibitors of JNK are being developed to treat arthritis and have been effective in models of experimentally induced arthritis and joint pain..$^{18} \mathrm{We}$ assessed the role played by the JNK MAPK pathway via the addition of a JNK MAPK inhibitor, SP600125 at $10 \mu \mathrm{M}$, and found significant downregulation of TNF $\alpha$, IL-6, and IL-8 production in cocultures of macrophage-like cells and IVD cells, but no significant effects on IL-6 and IL-8 production in nemotic AF and NP cells. These findings suggest that SP60012 may exert inhibitory effects on proinflammatory cytokine production during acute inflammatory reactions.
In the present study, we are trying to find a specific MAPK pathway during inflammatory reaction in IVD cells, which is major pain generator of symptomatic disc degeneration. The present study shows that inhibitors of $\mathrm{p} 38$ MAPK effectively controlled IL-6 production during acute and late inflammatory reactions and JNK and ERK1/2 inhibitors can successfully suppress the production of major proinflammatory cytokines during interactions between macrophage and IVD cells, which is an acute inflammatory reaction, although these inhibitors could not effectively control cytokine levels in nemotic IVD cells (representing the late stages of disc inflammatory reactions). Therefore, selective control of MAPK pathway activity may serve as a therapeutic strategy for the treatment of symptomatic intervertebral degeneration according to stage.

\section{Conclusions}

The present study shows that inhibitors of p38 MAPK effectively controlled IL-6 production during inflammatory reactions, and that JNK and ERK1/2 inhibitors successfully suppressed the production of major proinflammatory cytokines during acute inflammatory reaction. Therefore, selective blockade of these signals may serve as a therapeutic approach to symptomatic IVD degeneration.

\section{Acknowledgments}

This research was supported by the Basic Science Research Program through the National Research Foundation of Korea (NRF) and funded by the Ministry of Education, Science and Technology (NRF-2011-0021292). This work was approved by Korea 

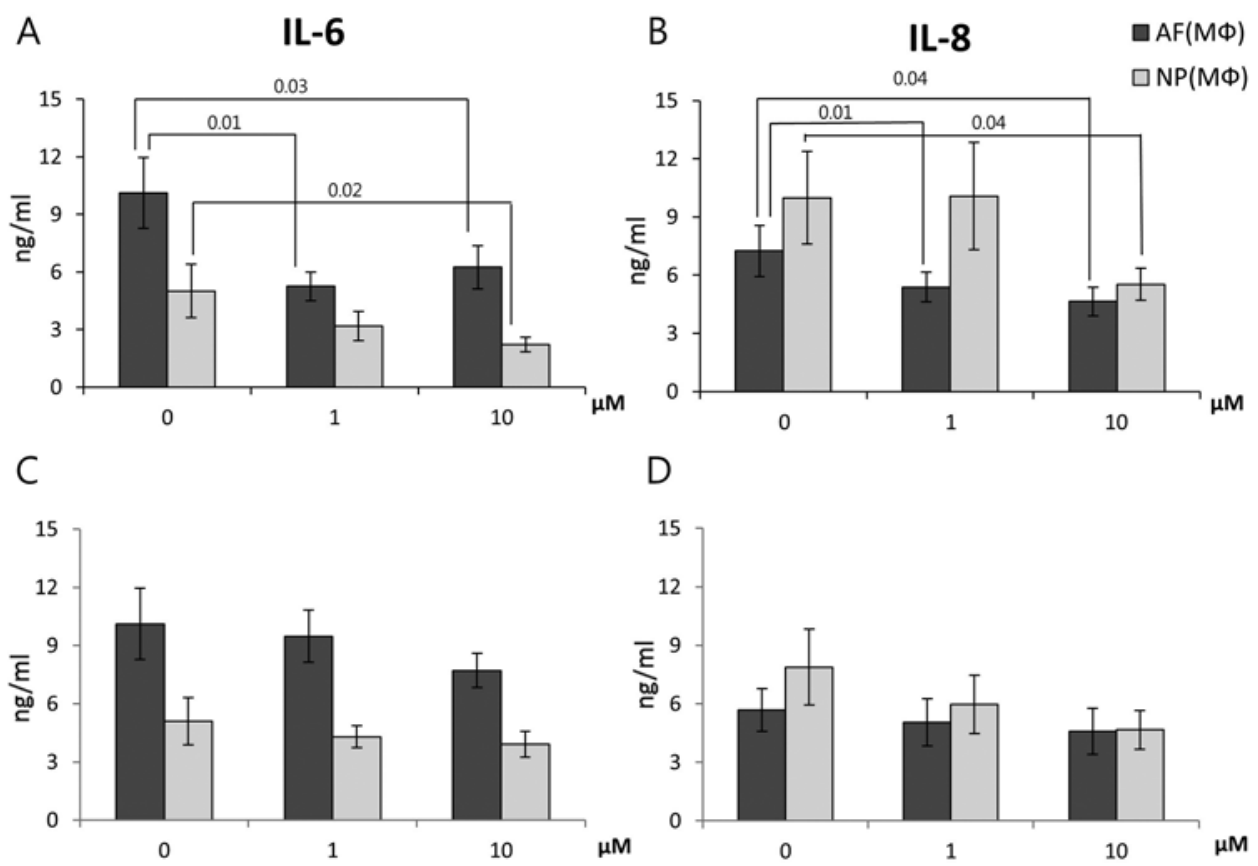

E

$\mathrm{F}$
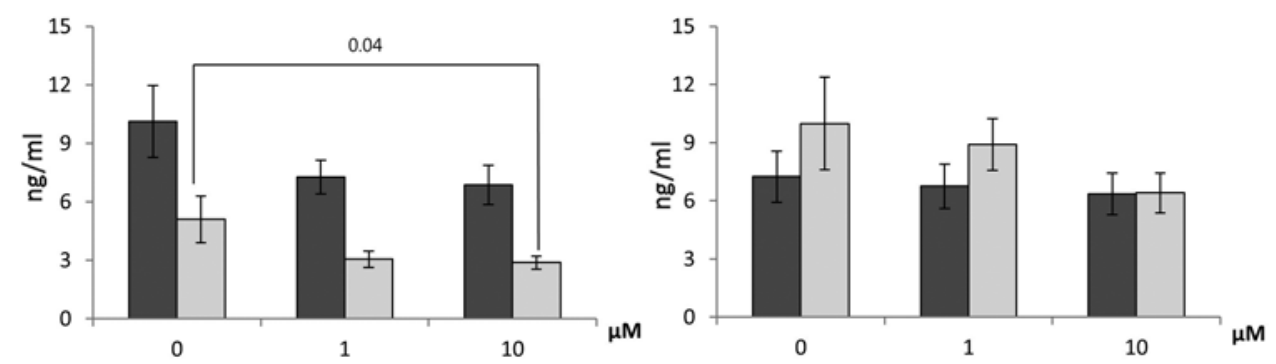

FIG. 7. A and B: Inhibition of the MAPK transduction pathway in macrophage-exposed (nemotic) AF and NP cells. SB202190 (10 $\mu \mathrm{M})$ dose-dependently decreased IL-6 and IL-8 production in nemotic [AF(M $\Phi)]$ and significantly decreased IL-6 and IL-8 production in nemotic [NP(MФ)]. C and D: SP600125 (10 $\mu \mathrm{M})$ did not significantly affect the production of IL-6 or IL-8 in AF(MФ) and $\mathrm{NP}(\mathrm{M} \Phi)$ cells, although the IL-6 level tended to decrease in $\mathrm{AF}(\mathrm{M} \Phi)$ as did IL-8 production in NP(MФ). $E$ and F: PD98059 at 10 $\mu \mathrm{M}$ significantly decreased IL-6 production in NP(MФ) and tended to decrease IL-6 production in AF(M $\Phi)$.

University Guro Hospital Institutional Review Board and Korea University Institutional Animal Care and Use Committee.

\section{References}

1. Buckwalter JA: Aging and degeneration of the human intervertebral disc. Spine (Phila Pa 1976) 20:1307-1314, 1995

2. Cui JG, Holmin S, Mathiesen T, Meyerson BA, Linderoth B: Possible role of inflammatory mediators in tactile hypersensitivity in rat models of mononeuropathy. Pain 88:239-248, 2000

3. Cunha FQ, Poole S, Lorenzetti BB, Ferreira SH: The pivotal role of tumour necrosis factor alpha in the development of inflammatory hyperalgesia. Br J Pharmacol 107:660-664, 1992

4. Damjanov N, Kauffman RS, Spencer-Green GT: Efficacy, pharmacodynamics, and safety of VX-702, a novel p38 MAPK inhibitor, in rheumatoid arthritis: results of two randomized, double-blind, placebo-controlled clinical studies. Arthritis Rheum 60:1232-1241, 2009

5. Dong C, Davis RJ, Flavell RA: MAP kinases in the immune response. Annu Rev Immunol 20:55-72, 2002
6. Gerlo S, Haegeman G, Vanden Berghe W: Transcriptional regulation of autocrine IL-6 expression in multiple myeloma cells. Cell Signal 20:1489-1496, 2008

7. Horner HA, Roberts S, Bielby RC, Menage J, Evans H, Urban JPG: Cells from different regions of the intervertebral disc: effect of culture system on matrix expression and cell phenotype. Spine (Phila Pa 1976) 27:1018-1028, 2002

8. Ji RR, Suter MR: p38 MAPK, microglial signaling, and neuropathic pain. Mol Pain 3:33, 2007

9. Kim JH, Studer RK, Sowa GA, Vo NV, Kang JD: Activated macrophage-like THP-1 cells modulate anulus fibrosus cell production of inflammatory mediators in response to cytokines. Spine (Phila Pa 1976) 33:2253-2259, 2008

10. Kim JH, Studer RK, Vo NV, Sowa GA, Kang JD: p38 MAPK inhibition selectively mitigates inflammatory mediators and VEGF production in AF cells co-cultured with activated macrophage-like THP-1 cells. Osteoarthritis Cartilage 17:1662-1669, 2009

11. Kishimoto T, Akira S, Taga T: Interleukin-6 and its receptor: a paradigm for cytokines. Science 258:593-597, 1992

12. Kloesch B, Liszt M, Steiner G, Bröll J: Inhibitors of p38 and ERK1/2 MAPkinase and hydrogen sulphide block constitutive and IL-1 $\beta$-induced IL- 6 and IL- 8 expression in the hu- 
man chondrocyte cell line C-28/I2. Rheumatol Int 32:729736, 2012

13. Koch A, Zacharowski K, Boehm O, Stevens M, Lipfert P, von Giesen HJ, et al: Nitric oxide and pro-inflammatory cytokines correlate with pain intensity in chronic pain patients. Inflamm Res 56:32-37, 2007

14. Kumar S, Votta BJ, Rieman DJ, Badger AM, Gowen M, Lee JC: IL-1- and TNF-induced bone resorption is mediated by p38 mitogen activated protein kinase. J Cell Physiol 187:294-303, 2001

15. Lappas M, Rice GE: The role and regulation of the nuclear factor kappa B signalling pathway in human labour. Placenta 28:543-556, 2007

16. Lee JY, Hall R, Pelinkovic D, Cassinelli E, Usas A, Gilbertson L, et al: New use of a three-dimensional pellet culture system for human intervertebral disc cells: initial characterization and potential use for tissue engineering. Spine (Phila Pa 1976) 26:2316-2322, 2001

17. Moon HJ, Kim JH, Lee HS, Chotai S, Kang JD, Suh JK, et al: Annulus fibrosus cells interact with neuron-like cells to modulate production of growth factors and cytokines in symptomatic disc degeneration. Spine (Phila Pa 1976) 37:29, 2012

18. Nieminen R, Leinonen S, Lahti A, Vuolteenaho K, Jalonen $\mathrm{U}$, Kankaanranta H, et al: Inhibitors of mitogen-activated protein kinases downregulate COX-2 expression in human chondrocytes. Mediators Inflamm 2005:249-255, 2005

19. Olsnes C, Olofsson J, Aarstad HJ: MAPKs ERK and p38, but not JNK phosphorylation, modulate IL- 6 and TNF- $\alpha$ secretion following OK-432 in vitro stimulation of purified human monocytes. Scand J Immunol 74:114-125, 2011

20. Oquendo J, Dubanchet S, Capel F, Mabit H, Petit MA: Suppressive effect of hepatitis $\mathrm{B}$ virus on the induction of interleukin- 1 beta and interleukin- 6 gene expression in the THP-1 human monocytic cell line. Eur Cytokine Netw 7:793-800, 1996

21. Peng B, Hao J, Hou S, Wu W, Jiang D, Fu X, et al: Possible pathogenesis of painful intervertebral disc degeneration. Spine (Phila Pa 1976) 31:560-566, 2006

22. Rovera G, Santoli D, Damsky C: Human promyelocytic leukemia cells in culture differentiate into macrophage-like cells when treated with a phorbol diester. Proc Natl Acad Sci U S A 76:2779-2783, 1979
23. Studer RK, Aboka AM, Gilbertson LG, Georgescu H, Sowa $\mathrm{G}$, Vo N, et al: p38 MAPK inhibition in nucleus pulposus cells: a potential target for treating intervertebral disc degeneration. Spine (Phila Pa 1976) 32:2827-2833, 2007

24. Su B, Karin M: Mitogen-activated protein kinase cascades and regulation of gene expression. Curr Opin Immunol 8:402-411, 1996

25. Tötterman TH, Nilsson K, Sundström C: Phorbol ester-induced differentiation of chronic lymphocytic leukaemia cells. Nature 288:176-178, 1980

26. Tsuchiya S, Kobayashi Y, Goto Y, Okumura H, Nakae S, Konno T, et al: Induction of maturation in cultured human monocytic leukemia cells by a phorbol diester. Cancer Res 42:1530-1536, 1982

27. Vermeulen L, De Wilde G, Van Damme P, Vanden Berghe $\mathrm{W}$, Haegeman G: Transcriptional activation of the NF- $\mathrm{KB}$ p65 subunit by mitogen- and stress-activated protein kinase-1 (MSK1). EMBO J 22:1313-1324, 2003

\section{Disclosure}

The authors report no conflict of interest concerning the materials or methods used in this study or the findings specified in this paper.

\section{Author Contributions}

Conception and design: all authors. Acquisition of data: Kim, JJ Park, Moon, JH Park. Analysis and interpretation of data: Kim, JJ Park, Moon, JH Park. Drafting the article: Kim, JJ Park. Critically revising the article: Kim, JJ Park, Moon, Kwon, YK Park. Reviewed submitted version of manuscript: Kim, JJ Park. Approved the final version of the manuscript on behalf of all authors: Kim. Statistical analysis: Kim, JJ Park, Moon. Administrative/technical/material support: Kim. Study supervision: Kim, YK Park.

\section{Correspondence}

Joo Han Kim, Department of Neurosurgery, Guro Hospital, College of Medicine, Korea University, 80, Guro-dong, Guro-gu 152-703, Seoul, South Korea. email: nskjh94@gmail.com. 